\title{
Ambient noise tomography in the Pantanal basin
}

\author{
Lúcio Quadros ${ }^{1}$, Marcelo Assumpção ${ }^{1}$ \\ ${ }^{1}$ Institute of Astronomy, Geophysics and Atmospheric Sciences
}

Copyright 2021, SBGf - Sociedade Brasileira de Geofísica.

This paper was prepared for presentation during the $17^{\text {th }}$ International Congress of the Brazilian Geophysical Society held in Rio de Janeiro, Brazil, 8-11 November 2021 (Online Event). Contents of this paper were reviewed by the Technical Committee of the $17^{\text {th }}$ International Congress of the Brazilian Geophysical Society and do not necessarily represent any position of the SBGf, its officers or members. Electronic reproduction or storage of any part of this paper for commercial purposes without the written consent of the Brazilian Geophysical Society is prohibited.

The South American Platform is composed of several tectonic units that have been continuously studied over the last decades. Throughout this time, little attention was given to the Pantanal basin, one of the largest intracratonic Cenozoic basins, present in an important region of the Andean foreland system with significant tectonic connections with the basins Chaco-Paraná, Paraná, and the Andes mountain range.

Over the years, several numerical and qualitative formation models for the Pantanal basin were proposed, however, the exact processes regarding the origin and evolution of the basin are still in debate. Recent studies identified a thin crust zone $(\sim 35 \mathrm{~km})$ east of the basin. The delamination of a mafic layer in the lower crust was proposed to explain this observation that could be linked to a weakness zone along the Transbrazilian Lineament below the basin.

This work is part of a Ph.D. program still in development that aims to do a seismic noise tomography using surface waves (Rayleigh and Love) to better characterize the crustal and sedimentary structure of the Pantanal basin. We will aim to validate the delamination hypothesis and better characterize the region aggregating receiver function and earthquake data to the tomographic results.

This study used data collected between 1999 and 2021 from 69 stations located in the central-west region of Brazil and Paraguay. The data processed yielded 629 station pairs with periods ranging from 2 to $64 \mathrm{~s}$ after taking into account quality measures. However, the dispersions provide enough data only for tomographic inversions between 4 and $30 \mathrm{~s}$. The identification of periods lower than $8 \mathrm{~s}$ is a new and promising result for the region that can enable a better characterization of the shallower depths of the crust. This result will be further enhanced with the deployment of 18 stations in the Basin in collaboration with the Chinese Academy of Geological Sciences.

We conducted a preliminary group velocity tomography using Rayleigh waves for the period of $4 \mathrm{~s}$ with velocities ranging from 2.4 to $3.2 \mathrm{~km} / \mathrm{s}$. Two main anomalies were observed: (1) lower velocities, below $2.6 \mathrm{~km} / \mathrm{s}$, with good correlation in areas of the Paraná basin where the sedimentary thickness can reach around $7 \mathrm{~km}$. (2) and higher velocities, above $2.8 \mathrm{~km} / \mathrm{s}$, that could be linked with the Pantanal basin basement. 